\title{
Cerebral palsy in adult patients: constraint-induced movement therapy is effective to reverse the nonuse of the affected upper limb
}

\author{
A eficácia da terapia por contensão induzida em pacientes adultos com paralisia cerebral \\ Ana Cecilia P. Oliveira1,2, Camila de Freitas ${ }^{2,3}$, Rafael Eras-Garcia ${ }^{2,4}$, Gabriela S. Matuti, , Juliana F. Santos ${ }^{2,5}$, \\ Clarissa B. Oliveira ${ }^{2,6}$
}

\begin{abstract}
Objective: To determine if the original protocol of Constraint-Induced Movement Therapy (CIMT), is adequate to reverse the nonuse of the affected upper limb (AUL) in patients with Cerebral Palsy (CP) in adulthood. Method: The study included 10 patients diagnosed with CP hemiparesis had attended the adult protocol CIMT, from January/August 2009/2014. Results: Average age 24.6 (SD 9.44); MAL average pretreatment How Often $(\mathrm{HO})=0.72$ and How Well $(\mathrm{HW})=0.68$ and post-treatment $\mathrm{HO}=3.77$ and $\mathrm{HW}=3.60(\mathrm{p} \leq 0.001)$ and pretreatment WMFT average $=21.03$ and post-treatment average $=18.91(p=0.350)$. Conclusion: The constraint-induced movement therapy is effective to reverse the nonuse learn of the AUL in adult patients with CP.
\end{abstract}

Keywords: cerebral palsy, adult, constraint-induced movement therapy.

RESUMO

Objetivo: Determinar se o protocolo original da Terapia por Contensão Induzida (TCI), é adequado para reverter o não uso do membro superior afetado (MSA) em pacientes com Paralisia Cerebral (PC) na fase adulta. Método: Foram incluídos no estudo 10 pacientes com diagnóstico de PC hemiparéticos que haviam realizado o protocolo adulto da TCI, no período de janeiro/2009 a agosto/2014. Resultados: Média de idade 24,6 (DP 9,44); MAL média pré-tratamento Quantidade $(\mathrm{QT})=0,72$ e Qualidade $(\mathrm{QL})=$ 0,68 e no pós-tratamento QT = 3,77 e QL = 3,60 $(p \leq 0,001)$ e WMFT média pré-tratamento = 21,03 e média pós-tratamento =18,91 ( $p=0,350)$. Conclusão: A terapia por contensão induzida é eficaz para reverter o não uso do MSA em pacientes adultos com PC.

Palavras-chave: paralisia cerebral, adulto, terapia por contensão induzida.

Cerebral Palsy (CP) describes a group of permanent disorders of movement and posture, not progressive, occurring in fetal or infant brain development causing limitations in performing activities of daily living (ADL's) $)^{1,2,3,4}$. Considering the topographic classification of $\mathrm{CP}$, the hemiplegia leads to impairment of the contralateral hemisphere brain injury, causing difficulties in the use of the affected upper limb (AUL) due to poor selective motor control, muscle weakness, stereotyped posture and sensorial deficit ${ }^{5}$.

The upper limb (UL) unaffected is the one to be used functionally, precluding bilateral movements and leading to compensatory movement patterns, which can exacerbate the established shortcomings ${ }^{6,7}$. To this effect is attributed to the term "nonuse learned" in which the AUL ceases to be used, not only by a motor condition, but by the occurrence of inadequate neuroplasticity of motor and somatosensory areas, enhancing the non-use of this segment in daily activities ${ }^{6,8}$.

Among the techniques of rehabilitation of the AUL, stands out the Constraint-Induced Movement Therapy (CIMT), which was developed by Edward Taub and coworkers at the University of Alabama at Birmingham (UAB), USA. Based on principles of neurobehavioral rehabilitation, it is based on three pillars: intensive training with repetition

'Universidade Federal do Triângulo Mineiro, Terapia Ocupacional, Uberaba MG, Brazil;

${ }^{2}$ Associação de Assistência à Criança Deficiente, Sao Paulo SP, Brazil;

${ }^{3}$ Universidade Federal de São Paulo, Terapia Ocupacional, Sao Paulo SP, Brazil;

«Universidade de São Paulo, Faculdade de Medicina de Ribeirão Preto, Terapia Ocupacional, Ribeirao Preto SP, Brazil;

${ }^{5}$ Faculdade de Ciências Humanas, Saúde e Educação de Guarulhos, Fisioterapia, Guarulhos SP, Brazil;

${ }^{6}$ Universidade de São Paulo, Faculdade de Medicina, Departamento de Neurologia, Sao Paulo SP, Brazil;

Correspondence: Ana Cecília P. Oliveira; Avenida Prof. Ascendino Reis, 724; 04027-000 São Paulo SP, Brasil; E-mail: cicapo@hotmail.com

Conflict of interest: There is no conflict of interest to declare.

Received 12 February 2015; Received in final form 05 August 2015; Accepted 25 August 2015. 
(shaping and task practice), restricting unaffected UL (glove or plaster) and package of behavioral methods, which aim to transfer the gains out of therapeutic environment ${ }^{8,9}$. Studies show that CIMT is able to reverse the learned nonuse in patients with stroke, and maintain these results for a long period, as shown by Wolf and coworkers ${ }^{10}$ in a randomized clinical trial with a sample of 70 individuals. Recent clinical trials demonstrate that the CIMT is effective in treating children and adolescents with CP and adults with hemiparesis after brain lesions, with a significant increase in the spontaneous use of AUL in ADL's ${ }^{11}$. The aim of this study is to determine if the original protocol CIMT is adequate to reverse the nonuse of AUL in adult patients with CP.

\section{METHOD}

This retrospective study included 10 patients from January of 2009 to August of 2014.

The inclusion criteria were: diagnosis of $\mathrm{CP}$ spastic hemiparesis, aged from 16 years; presence of active AUL motor function, grade 2 in accordance with the grade criteria (Table 1$)^{12}$; to be able to respond to simple commands; to be available to attend all days consecutively ( 12 days for the adult protocol); to be able to remain in therapy for 3 hours/day; asymmetrical use of the UL's (score lower than 2.5 on the scale Motor Activity Log - MAL); adequate vision/hearing and proper balance.

The training of AUL used the technique of shaping, characterized by the repetition of parts of functional task and task practice, which refers to the practice of complete functional tasks carried out to simulate everyday activities, ${ }^{913}$.

The patients received a daily application of behavioral package: within 30 minutes of therapy, compounded by
Behavioral Contract and the apparatus for restricting the unaffected UL; daily administration of MAL (15 questions per day); Home Diary and List of Daily Tasks.

The patients were evaluated using scales MAL and Wolf Motor Function Test (WMFT).

The MAL is a scale presented as a structured interview, subdivided in two domains: "How Often" (HO) and "How Well" (HW) regarding the use of the AUL outside therapeutic environment ${ }^{15}$. Both domains are scored from 0 to 5 points. In the HO domain 0 means "I did not use the weaker arm for the activity" and 5 "The weaker arm was used as much as the strongest arm to do the activity (always) ${ }^{14}$. In the HW domain 0 means "I did not use the weaker arm for the activity" and 5 "The weaker arm did the activity normally" ${ }^{14}$.

The WMFT measures the performance time and functional ability during the execution of the 15 functional tasks ${ }^{15}$. For this research only the performance time portion of the test was used. The total score of the performance was calculated by the average time for all tasks. When the individual is unable to execute the task, is assigned a score of 121 seconds, because 120 seconds is the maximum time allowed for the individual to execute the task ${ }^{15}$.

Post hoc analysis was performed considering the means and standard deviations, considering the main objective of the study. Paired t-test considering $\alpha=0.05$, bi-cauded analysis and sample of 10 patients were used. Both scales MAL HO and HW showed $\beta=1.0$, and effect size of 4.61 , and 4.63 respectively. Only the WMFT scale showed $\beta=0.07$ and effect size of 0.14 .

The characterization data of the sample are presented in a descriptive way, considering the mean and standard deviation for quantitative variables and percentages for qualitative variables. The study variables were tested for distribution using the Kolmogorov-Smirnov test. Being parametric, was used the paired Student $\mathrm{T}$ test to analyze the effects of CIMT, considering $\mathrm{p}<0.05$, and the outcome variables the how

Table 1. Grade criteria ${ }^{12}$.

\begin{tabular}{|c|c|c|c|c|c|}
\hline & Shoulder & Elbow & Wrist & Fingers & Thumb \\
\hline $\begin{array}{l}\text { Grade } 2(\mathrm{MAL}<2.5 \text { for } \\
\mathrm{HO} \& \mathrm{HW} \text { scale) }\end{array}$ & $\begin{array}{l}\text { Flexion } \geq 45^{\circ} \text { and } \\
\text { Abduction } \geq 45^{\circ}\end{array}$ & $\begin{array}{l}\text { Extension } \geq 20^{\circ} \text { from a } 90^{\circ} \\
\text { flexed starting position }\end{array}$ & $\begin{array}{l}\text { Extension } \\
\quad \geq 20^{\circ}\end{array}$ & $\begin{array}{l}\text { Extension of all MCP \& IP } \\
\text { (either PIP or DIP) joints } \geq 10^{\circ}\end{array}$ & $\begin{array}{l}\text { Extension or } \\
\text { abduction of } \\
\text { thumb } \geq 10^{\circ}\end{array}$ \\
\hline $\begin{array}{l}\text { Grade } 3(\mathrm{MAL}<2.5 \text { for } \\
\mathrm{HO} \& \mathrm{HW} \text { scale) }\end{array}$ & $\begin{array}{l}\text { Flexion } \geq 45^{\circ} \text { and } \\
\text { Abduction } \geq 45^{\circ}\end{array}$ & $\begin{array}{l}\text { Extension } \geq 20^{\circ} \text { from a } 90^{\circ} \\
\text { flexed starting position }\end{array}$ & $\begin{array}{l}\text { Extension } \\
\quad \geq 10^{\circ}\end{array}$ & $\begin{array}{l}\text { Extension of MCP \& IP (either } \\
\text { PIP or DIP) joints of at least } \\
2 \text { fingers } \geq 10^{\circ}\end{array}$ & $\begin{array}{l}\text { Extension or } \\
\text { abduction of } \\
\text { thumb } \geq 10^{\circ}\end{array}$ \\
\hline $\begin{array}{l}\text { Grade } 4(\mathrm{MAL}<2.5 \text { for } \\
\mathrm{HO} \& \mathrm{HW} \text { scale })\end{array}$ & $\begin{array}{l}\text { Flexion } \geq 45^{\circ} \text { and } \\
\text { Abduction } \geq 45^{\circ}\end{array}$ & $\begin{array}{l}\text { Extension } \geq 20^{\circ} \text { from a } 90^{\circ} \\
\text { flexed starting position }\end{array}$ & $\begin{array}{l}\text { Extension } \\
\quad \geq 10^{\circ}\end{array}$ & $\begin{array}{l}\text { Extension of at least } \\
2 \text { fingers }>0^{\circ} \&<10^{\circ}\end{array}$ & $\begin{array}{l}\text { Extension or } \\
\text { abduction of } \\
\text { thumb } \geq 10^{\circ}\end{array}$ \\
\hline $\begin{array}{l}\text { Grade } 5(\mathrm{G} 4 / 5 \\
M A L<2.5 \text { for } \mathrm{HO} \& \\
\text { HW scale) Subclass A }\end{array}$ & $\begin{array}{c}\text { Flexion } \geq 30^{\circ}, \text { Abduction } \geq 30^{\circ} \\
\text { or Scaption } \geq 30^{\circ}\end{array}$ & $\begin{array}{l}\text { Initiation* of both flexion } \\
\text { and extension }\end{array}$ & \multicolumn{3}{|c|}{$\begin{array}{l}\text { Must be able to either initiate* extension of the wrist } \\
\text { or initiate* extension of any digit }\end{array}$} \\
\hline Subclass B & $\begin{array}{c}\text { Flexion } \geq 30^{\circ}, \text { Abduction } \geq 30^{\circ} \\
\text { or Scaption } \geq 30^{\circ}\end{array}$ & $\begin{array}{l}\text { Extension } \geq 20^{\circ} \text { from a } 90^{\circ} \\
\text { flexed starting position }\end{array}$ & \multicolumn{3}{|c|}{$\begin{array}{c}\text { No active movement required at the wrist, fingers, } \\
\text { or thumb }\end{array}$} \\
\hline
\end{tabular}


often and how well of use outside the therapeutic environment and the speed of the AUL.

\section{RESULTS}

The characterization of the sample is shown in Table 2. All patients in the study showed significant improvement when comparing pre and post-treatment of MAL scale $(p<0.05)$, in how often and how well of the AUL. There was also a decrease in the duration performance of movements assessed by the WMFT, but this difference was not significant $(\mathrm{p}=0.350)$ (Table 3$)$.

\section{DISCUSSION}

Considering the higher life expectation of this population, other functional demands arise, such as work activities, leisure, social participation and instrumental activities of daily living. For this reason, it is necessary to apply interventions that optimize the functions of the AUL in hemiparesis, highlighting the CIMT technique currently level A scientific evidence for adult patients.

The literature demonstrates that the technique is effective for reversing of learned nonuse through plastic changes, demonstrated in changes in brain structure, accompanied by improved motor function and use of AUL in everyday activities, both in adult patients with acquired brain lesions, as in children and adolescents with $\mathrm{CP}^{11,16}$.

The present study demonstrated that the original protocol of CIMT was adequate to reverse the learned nonuse of AUL in adult patients with CP. Through MAL scale was possible to observe a significant improvement in the usage

Table 2. The characterization of the sample.

\begin{tabular}{|c|c|c|c|c|}
\hline Age & Gender & GMFCS & $\begin{array}{c}\text { Topographic } \\
\text { diagnosis }\end{array}$ & $\begin{array}{l}\text { Motor } \\
\text { level }\end{array}$ \\
\hline \multirow[t]{2}{*}{$\begin{array}{l}\text { Average }=24.60 \\
(S D=9.44)\end{array}$} & $\begin{array}{c}\text { Female } \\
60 \%\end{array}$ & $\begin{array}{l}\text { Level II } \\
80 \%\end{array}$ & $\begin{array}{l}\text { Right Side } \\
70 \%\end{array}$ & $\begin{array}{c}\text { Level } 2 \\
100 \%\end{array}$ \\
\hline & $\begin{array}{l}\text { Male } \\
40 \%\end{array}$ & $\begin{array}{l}\text { Level III } \\
20 \%\end{array}$ & $\begin{array}{l}\text { Left Side } \\
30 \%\end{array}$ & \\
\hline
\end{tabular}

SD: Standard Deviation; GMFCS: Gross Motor Function Classification System.

Table 3. The Results of CIMT in adult patients with CP.

\begin{tabular}{lcccc} 
& N & Average & SD & p-value \\
\hline MAL HO (Pre) & 10 & 0.72 & 0.58 & \\
MAL HO (Post) & & 3.77 & 0.72 & $<0,001$ \\
MAL HW (Pre) & & 0.68 & 0.49 & \\
MAL HW (Post) & & 3.60 & 0.71 & \\
WMFT (Pre) & & 21.03 & 15.09 & \\
WMFT (Post) & & 18.91 & 13.62 & 0,350
\end{tabular}

MAL: Motor Activity Log; HO: how often the patient used the AUL; HW: how well patient's perception regarding quality of use of the AUL; WMFT: Wolf Motor Function Test. amount, wherein the average pretreatment was 0.72 (AUL rarely used) to $3.77(\mathrm{p}<0.001)$ in the after treatment, which means that the patient has been using the AUL in $50-75 \%$ of activities. Regarding the quality of the movement, was also observed significant improvement in the average pretreatment was 0.68 (the AUL is not used or is moved to the activity, but not useful), while the average post-treatment was 3.60 $(p<0.001)$, which demonstrates an improvement in the perception of patients about the quality of movement, changing to a quality between regular and almost normal.

Adult patients with CP, mostly spent years in the rehabilitation process and for this reason have already made multiple interventions such as occupational therapy, physiotherapy, surgical procedures, peripheral blocks chemicals, among others. The quality of movement has been extensively explored during this period, as showed in the WMFT scale results, but even some activities being performed more slowly, their perception about the quality of the movement was enlarged, showing a greater recognition of this member during the functional use.

The CIMT is a technique that is designed to improve the use of upper limb in functional activities for stroke patients. The CIT protocol was then modified for children with CP, with some differences, such as the duration (3 hours/day for 15 days) and restriction with plaster, in which data proving the effectiveness of the technique were found in this population $^{11,16}$. However, the use of pediatric protocol cannot be done with an adult population, as the study in question, since people are functionally engaged in activities that do not allow the limitation of UL unaffected by a period as long as the pediatric protocol (work, travel and study). However, it is known from the literature, that the restriction of UL unaffected is not the most important pillar of the technique in patients with acquired brain lesions, but the implementation of the package of behavioral methods that can make the transfer of the gains made in therapy to the living environment of the patient ${ }^{17}$.

Studies that compare the results of the technique through imaging exams (diffusion imaging) in children with CP and adults with Stroke, found that in children the same changes occur in the gray matter in the motor areas of the brain and hippocampus found in adults, leading to an improvement of motor function of the affected upper limb $b^{11,16}$.

It is known that brain plasticity is higher in young children because the central nervous system is still in early phases of development. In contrast, the neural substrates for the hand control continues to develop during the first two decades of life, whereas the process of plasticity occurs in a continuous manner, ${ }^{7,18,19}$. The significant improvement in adults may be related to increased attention and participation during structured practice and greater motivation towards improved function, because a broader awareness of their limitations and desire for social inclusion ${ }^{7,18}$.

The extrinsic factors may also influence the results of treatment of adult patients, as the economic and socio-cultural 
context in which they are inserted. The CIMT requires significant involvement of caregivers and family members in the pediatric protocol and of the own patient when adult, especially for the realization of behavioral package, but studies examining the predictors of technical developments in other countries, have not reached a consensus on the influence of these aspects of the results of $\mathrm{CIMT}^{7,18,20}$.

We conclude that constraint-induced movement therapy is effective to reverse the nonuse of the affected upper limb in adult patients with cerebral palsy.

\section{References}

1. Rosenbaum P, Paneth N, Leviton A, Goldstein M, Bax M. A report: the definition and classification of cerebral plasy april 2006. Dev Med Child Neurol Suppl. 2007;49(suppl 109):8-14. doi:10.1111/j.1469-8749.2007.tb12610.x

2. Margre ALM, Reis MGL, Morais RLS. Caracterização de adultos com paralisia. Rev Bras Fisioter. 2010;14(5):417-25. doi:10.1590/S1413-35552010000500011

3. Strauss D, Brooks J, Rosenbloom L, Shavelle R. Life expectancy in cerebral palsy: an update. Dev Med Child Neurol. 2008;50(7):487-93. doi:10.1111/j.1469-8749.2008.03000.x

4. Ministério da Saúde (BR), Secretaria de Atenção à Saúde. Diretrizes de atenção à pessoa com paralisia cerebral. Brasília, DF: Ministério da Saúde; 2013

5. Hoare BJ, Imms C, Rawicki HB, Carey L. Modified constraint-induced movement therapy or bimanual occupational therapy following injection of Botulinum toxin-A to improve bimanual performance in young children with hemiplegic cerebral palsy: a randomised controlled trial methods paper. BMC Neurol. 2010;10(1):58. doi:10.1186/1471-2377-10-58

6. Brol AM, Bortoloto F, Magagnin NMS. Tratamento de restrição e indução do movimento na reabilitação funcional de pacientes pós acidente vascular encefálico: uma revisão bibliográfica. Fisioter Mov. 2009;22(4):497-509.

7. Gordon AM, Charles J, Wolf SL. Efficacy of constraint-induced movement therapy on involved upper-extremity use in children with hemiplegic cerebral palsy is not age-dependent. Pediatrics. 2006;117(3):e363-73. doi:10.1542/peds.2005-1009

8. Taub E, Uswatte G, Mark VW, Morris DM. The learned nonuse phenomenon: implications for reahabilitation. Eura Medicophys. 2006;42(3):241-56.

9. Taub E, Uswatte G. Constraint-induced movement therapy: briding from the primate laboratory to the stroke rehabilitation laboratory. $J$ Rehabil Med. 2003;35(41):34-40. doi:10.1080/16501960310010124

10. Wolf SL, Winstein CJ, Miller JP, Thompson PA, Taub E, Uswatte G et al. The excite trial: retention of improved upper extremity function among survivors receiving $\mathrm{Cl}$ movement therapy. Lancet. Neurol. 2008;7(1):33-40. doi:10.1016/S1474-4422(07)70294-6

11. Sterling C, Taub E, Davis D, Rickards T, Gauthier LV, Griffini A, Uswatte G. Structural neuroplastic change after constraint-induced movement therapy in children with cerebral palsy. Pediatrics. 2013;131(5):e1664-9. doi:10.1542/peds.2012-2051

12. Taub E, Uswatte G, Mark WV, Morris DM, Barman J, Bowman $\mathrm{MH}$ et al. Method for enhancing real-world use of a more affected arm in chronic stroke: transfer package of constraint-induced movement therapy. Stroke. 2013;44(5):1383-8. doi:10.1161/STROKEAHA.111.000559

13. Taub E. The behavior-analytic origins of constraint-induced movement therapy: an example of behavioral neurorehabilitation. Behav Anal. 2012;35(2):155-78.

14. Saliba VA, Magalhães LC, Faria CDCM, Laurentino GEC, Cassiano JG, Salmela LFT. Adaptação transcultura e análise das propriedades psicométricas da versão brasileira do instrumento Motor Activity Log. Rev Panam Salud Publica. 2011;30(3):262-71. doi:10.1590/S1020-49892011000900011

15. Pereira ND, Michaelsen SM, Menezes IS, Ovando AC, Lima RCM, Salmela LFT. Confiabilidade da versão brasileira do Wolf Motor Function Test em adultos com hemiparesia. Rev Bras Fisoter. 2011;15(3):257-65. doi:10.1590/S1413-35552011000300013

16. Rickards T, Sterling C, Taub E, Perkins-Hu C, Gauthier L, Graham $M$ et al. Diffusion tensor imaging study of the response to constraint-induced movement therapy of children with hemiparetic cerebral palsy and adults with chronic stroke. Arch Physical Med Rehabil. 2014;95(3):506-14e1. doi:10.1016/j.apmr.2013.08.245

17. Wolf SL. Revisiting constraint induced movement therapy: are we too smitten with the mitten? Is all nonuse "learned"? and other quandaries. Phys Ther. 2007;87(9):1212-23. doi:10.2522/ptj.20060355

18. De Paula TO, Nagano GT, Lima GN, Santos JF, Silva ACR. A efetividade da terapia por contensão induzida no membro superior de pacientes com paralisia cerebral. Fisio Brasil. 2014;15(4):269-76.

19. Nezu A, Kimura S, Uehara S, Kobayashi T, Tanaka M, Saito K. Magnetic stimulation of motor cortex in children: maturity of corticospinal pathway and problem of clinical application. Brain Dev. 1997;19(3):176-80. doi:10.1016/S0387-7604(96)00552-9

20. Deppe W, Thuemmler K, Fleischer J, Berger C, Meyer S, Wiedemann B. Modified constraint-induced movement therapy versus intensive bimanual training for children with hemiplegia: a randomized controlled trial. Clinical Rehabil. 2013;27(10):909-20. doi:10.1177/0269215513483764 